\title{
Analysis on the Measures to Improve Compensation Management in SMEs in China
}

\author{
Xinghua $\mathrm{Su}$ \\ Langfang Teacher's College \\ LangFang HeBei China \\ E-mail: sxhhrm@163.com
}

\begin{abstract}
The paper first analyzes the problems of compensation management in SMEs (small and medium-sized enterprises) in China. Besides, the paper combines with practical cases and puts forward suggestions and measures on improving the compensation management system in SMEs in China accordingly, aiming at providing help for the human resource managers in SMEs.
\end{abstract}

Keywords: SMEs; compensation management; measure; analysis

\section{INTRODUCTION}

Since the 1990s, the SMEs in China has rapidly developed and made great achievements. They have become an important component in national economy. However, because human resource management in SMEs in our country started at a late period and the foundations were rather weak, a number of problems emerged. In particular, the unreasonable and nonstandard compensation management has hindered the further development of SMEs. As a result, in order to strengthen the market competition, attract and retain key employees, SMEs must carry out profound analysis into the problems in their compensation management under the guidance of scientific management notions. On this basis, they should formulate appropriate compensation system to maximize the incentive functions of compensation, boost employees' initiatives and ultimately enhance the comprehensive competitiveness of SMEs.

\section{PROBlEMS IN COMPENSATION MANAGEMENT IN SMES IN CHINA}

When designing the compensation system, SMEs consider more about technology, approaches and other factors and ignore some significant decision-making in other aspects. With the rapid economic development in China and the shock of globalization, SMEs are encountering more and more fierce challenges. The problems in compensation management appear more salient, which are manifested in the following aspects.

\section{A. Disconnection between Compensation Management and Corporate Strategies}

When formulating compensation system, SMEs in our country consider more about technology, approaches, tools and other factors. However, there is an absence of comprehensive strategic contemplation. Corporate strategy serves as the longterm plan and a forceful tool to gain competitive advantages in the enterprises. Compensation management must be coordinated with overall corporate strategy and human resource strategy, thus functioning as an important supportive method to realize the corporate strategy. In particular, it is of great significance for SMEs to formulate compensation strategies, which exerts effects on whether they can attract and retain talents. However, at present, the majority of SMEs in China do not design their compensation management system from the perspective of their corporate strategy. They do not consider combining compensation management with the corporate strategy. As a result, there is a severe disconnection between compensation management and goals of the corporate strategy.

\section{B. Unreasonable Performance Appraisal and Poor Incentives of Compensation}

The SMEs in China all adopt performance-based compensation system, i.e., employees' compensation is composed of fixed compensation and performance-based compensation. However, the fact is that employees' compensation is not connected with their performance in essence. First and foremost, it is because of the large proportion of fixed compensation in the system, even reaching $90 \%$. The low ratio of performance-based compensation fails to stimulate employees' initiatives and creativity. Second, the performancebased compensation system in SMEs is established based on the long-term goal, which results in employees' little focus on the long-term development goal of the enterprises. In addition, they cannot enjoy the benefits that the corporate long-term goal will bring. Last, most SMEs do not have scientific and reasonable performance evaluation standards, which causes the failure to give accurate assessment on employees' performance. As a result, the compensation cannot match the performance, thus the incentives of compensation are weakened. Therefore, how to reach a reasonable composition of compensation and establish rational and reasonable performance evaluation system is a key aspect worth the managers' concerns in SMEs.

\section{Compensation Level'S Lack of External Competitiveness}

Restricted by the small corporate scale, financial support and other factors, the SMEs in China cannot stand too high labor cost. Therefore, the employees' comprehensive compensation level is lower than the average market level. Besides, SMEs carry out few investigations into the market compensation level. Even if they launch some investigations passively, the scope is quite limited. The SMEs only briefly understand the overall compensation level on the market. The 
lack of authenticity of data they obtain results in the absence of rationality of the compensation level. In addition, the position evaluation system in SMEs is not well-improved. The compensation standard in many SMEs does not base on the significance and contributions of the employees. Instead, it is determined by the corporate managers subjectively without explicit basis and rationality, which thereby causes the lack of competitiveness in SMEs and severely destroys employees' initiatives. Sometimes, it even leads to employee drainage.

\section{Incomplete Employee Welfare System}

Employee welfare is an important part in corporate compensation system. It is the reward for employees in the form of physical objects or services provided by the enterprises. Welfare can satisfy employees' demands in different aspects, thus forming short-term, middle-term and long-term incentives together with basic compensation and bonus. In many SMEs, however, welfare does not arouse the manager's adequate attention. Hence the welfare system in SMEs is not complete. Many managers in SMEs even deem welfare as cost burden. They invest a little into employees' welfare. Moreover, some SMEs even do not conform to the national laws and stipulations in terms of "Five insurances and pensions", let alone their own welfare in the enterprises. Furthermore, although some SMEs have their own welfare system, they only clarify the welfare items when the corporate benefits are sound. Such a system lacks pertinence and guarantee at the mechanism level. In addition, it does not take into consideration the actual situation of the enterprises and real needs of employees. In a word, the welfare items have no incentives.

\section{E. Ignore the Application of Non-Economic Pay}

Besides the basic compensation, performance-based compensation, welfare and other economicpay, there are also non-economic pay in the enterprises which includes participation into corporate decision-making, the balance between work and family, autonomy of work, challenging work and opportunity for personal development, etc. Relevant psychological researches indicate that economic pay can only encourage employees in a middle and short term. However, non-economic pay can form long-term incentives among employees and enhance their satisfaction. Many SMEs tend to ignore the non-economic pay for employees when designing the compensation system, however. They regard economic pay as the only one approach to encourage employees. They mistakenly believe that as long as they pay enough compensation, they can stimulate employees' initiatives. Under the effect of such a wrong idea, employees in SMEs cannot gain the spiritual satisfaction. As a result, their sense of belonging to the enterprises and faithfulness reduces, thus weakening their working efficiency.

\section{F. Absence of Effective Compensation Negotiation Mechanism}

Many SMEs in China adopt compensation secrecy system. However, a majority of employees are sensitive toward the fairness of compensation policy. The compensation secrecy system may arouse doubt toward the compensation system, thus reducing the employee satisfaction. Besides explaining employees' doubts, effective compensation negotiation can also convey the value and corporate culture orientation to employees and correctly guide their behaviors. Besides, compensation can also effectively enable managers to spot out the problems in corporate compensation management, thus facilitating the solution of the internal contradictions inside the corporate and eliminating their dissatisfaction. As a result, the lack of effective compensation management is also one important reason for the low efficiency of compensation management.

\section{PERFECT THE MEASURES FOR COMPENSATION MANAGEMENT IN SMES IN CHINA}

From the above analysis, we can see that the compensation management system in SMEs in China has numerous problems which severely hinder the promotion of the management in the enterprises. If SMEs seek for sustainable and rapid development, they must apply scientific technology and approaches and combine their own actual situation to improve the above problems in order to retain and stimulate the employees.

\section{A. Compensation Management should Combine with Corporate Strategy}

SMEs should clarify their corporate strategy primarily in order to perfect their compensation management. Generally speaking, the corporate strategy can be divided into two levels: first, the development strategy of the enterprise, i.e., to figure out the problem about expanding the scale, keeping the status quo or narrowing the scale; second, the competition strategy, i.e., to obtain competitive advantages through product innovation, low cost or providing services for regular customers. Different strategies selected by the enterprises will also generate varied compensation management strategies. Only when the compensation strategy matches the strategy of corporate development and competition can it really adapt to the demands of the enterprises' development so as to push forward the development of the enterprises.

For those SMEs lack long-term strategies and plans, the managers should first inspect the corporate vision and operational goals and clarify the main areas where the enterprises want to achieve success to select their own competition strategy, based on which SMEs can determine their human resource strategy and compensation strategy. In addition, they can further transform the compensation strategy into detailed compensation system and compensation management procedure. In doing so, SMEs can link the corporate strategy and employees' personal demands by means of compensation management. As a result, the compensation can effectively guide employees' attitudes and behaviors, instruct them to focus on obtaining competitive advantages for the enterprises, formulate common values and goals among employees and enterprises, maximize the effects of compensation and better retain and encourage the talents needed by SMEs. 


\section{B. Perfect performance-based Appraisal System and Strengthen the Incentive of Compensation System}

The formulation of compensation structure in SMEs serves as a guide to employees' behaviors. If the fixed compensation takes a large part in the compensation structure in the enterprises, it will weaken the incentive function of salary. As a result, SMEs should reasonably increase the percentage of performance-based compensation in the whole structure. Moreover, the percentage of performance-based compensation should increase with the elevation of the position level and the responsibilities so that SMEs can really realize the connection between employees' compensation and their performance. Therefore, the compensation system can give full play to its positive incentive roles.

Because the results of performance appraisal are directly linked with employees' compensation, the rationality ad fairness of performance-based appraisal directly affect the reasonableness of the compensation system. In order to guarantee the appropriateness and effectiveness of the performance appraisal system, SMEs can apply the notion of balanced scorecard into the design of performance appraisal system from four perspectives, i.e., finance, customer satisfaction, internal operation, employee learning and growth. Then SMEs can decompose key company-level performance indicators to each department which formulates departmental performance plan in accordance with the business characteristics in the department. Finally, the departmental goals can be decomposed to each post. In this way, through level-to-level decomposition, SMEs can scientifically and reasonably determine the key performance indicators in each department and position. Therefore, the comprehensive performance indicator system from enterprises to individuals can be reached ultimately.

\section{Carry out Compensation Investigation to Ensure the External Competitiveness of the Compensation System in SMEs}

The compensation level with external competitiveness can help SMEs attract, retain and stimulate employees, especially the most excellent employees in the enterprises. Low compensation level might cause the drainage of employees. Therefore, SMEs have to know clearly the compensation status in their competitor companies so as to make competitive compensation management strategy.

Compensation investigation refers to the activity providing basis for managers' decision-making by exploring into the compensation level and structure of relevant positions in a certain scale with some scientific methods. Through compensation investigation, SMEs can provide the compensation with external competitiveness and guarantee the effectiveness of the expenses on labor cost. SMEs can obtain the data and information about compensation through telephone interview, investigation questionnaires, communication with other enterprises and management consultation companies. The information and data include both the compensation level of corresponding positions in other companies in the same industry and the average compensation level on the local talent market. Through the data and information, we can find and improve the problems in the compensation system of the enterprises and provide basis for managers' decision-making. At the same time, through the analysis on the data and information, we can predict the market compensation level in a certain period in the future, thus providing basis for compensation decision-making in the next step.

According to the results of compensation investigation, SMEs can position the compensation level of core employees above the average market compensation level and pay the highlevel managers, key technical and sales talents and other core employees with higher compensation than the average market compensation level. For those who can be easily recruited on the labor market, we can determine their compensation in accordance with the average market level. In this way, we can reasonably control labor cost and alleviate the corporate burden.

\section{Perfect Welfare Items and Design Diverse Welfare System}

Welfare can satisfy employees' demands in different aspects, so SMEs must perfect and bring forth new welfare system. On the prerequisite of implementing welfare regulated by laws, SMEs should design diverse welfare items in accordance with the enterprises' own characteristics and employees' demands to enhance the effectiveness of welfare cost.

In terms of perfecting the welfare system, SMEs should first carry out welfare investigation which includes the survey into the welfare situation in other enterprises and the adjustment on the employees' welfare needs. Through understanding competitors' welfare situation, SMEs can design and adjust their welfare system accordingly, thus maintaining their competitiveness in external labor market. The investigation into competitors' welfare system can be carried out simultaneously with compensation investigation as part of it. Different staff may have varied welfare demands and biases. Therefore, the welfare investigation among employees enables the new welfare system to be more pertinent. Besides, the investigation among the employees can be implemented through questionnaires and interview. SMEs can also provide personalized welfare items for employees according to the investigation results.

SMEs should notice two problems when perfecting the welfare system, i.e., the financial situation and the effectiveness of welfare expenses. The perfection of welfare system should be within the financial tolerance of the enterprises. Besides enhancing employee satisfaction, scientific welfare system should also deliver some information orientation to employees, such as the welfare system should be connected to employees' performance, corporate strategy, enterprise culture and so on.

\section{E. Give Full Play to the Effects of Non-Economic Pay}

Employees' demands are multilayered. Besides economic pay, employees also want some internal return, such as challenging work, sound opportunity for personal development, sense of career achievement, participation into decision-making, autonomy of work, etc. If SMEs can provide more opportunities for employees to develop their career, participate into decision-making and increase their autonomous right and 
other non-economic benefits which then can better activate the employees' contributions to the enterprises and promote the enterprises' development. If the employees lack the development opportunities, their work and family will be imbalanced without recognition from others. They will also feel bored and fed up with their work. Even if enterprises make great sacrifices, it is hard for them to reach the effect of stimulating employees' initiatives.

SMEs can play the role of non-economic returns through multiple means, such as creating excellent enterprise culture, forging positive enterprise atmosphere and uniting employees with enterprises to work hard toward the common mission and purposes. The enterprises should also pay attention to the challenges of the work and employees' career planning. The challenges and sound prospects of the work can stimulate employees' passion and fully excavate their potentials. SMEs can also pay attention to emotional investment and formulate favorable communication mechanism and atmosphere among managers and employees. Employees and enterprises can establish the partnership based on mutual understanding, trust and respect. Through the application of above non-economic returns, the dual goal of the co-growth of SMEs and employees and realization of employees' self values can be realized.

\section{F. Establish Effective Compensation Negotiation Mechanism}

Effective compensation communication can eliminate employees' confusions, enhance employees' trust on the enterprises and realize the internal transparency of compensation management system. SMEs can communicate with the professionals and employees who are familiar with the compensation system. The staff members can be experts from human resource department or financial department. They can also be the high-level administrators in charge of human resource management. In order to improve the efficiency of the communication in terms of compensation, managers in the human resource department can first understand the employees' comprehension, doubts, opinions and suggestions on the compensation system in the enterprises. On the basis, the managers can formulate the communication strategies in terms of the contents and modes of communication. The enterprises can also carry out communications with employees by means of bulletin board, internal journals, theme meeting and so on. Besides, they should also pay attention to the timeliness of communications so as to find out problems and correct them in time.

\section{CONCLUSION}

As an important component in human resource management, compensation management is of vital significance to the sustainable development in SMEs in China. As for these enterprises, they should formulate the compensation strategies suitable to their own development and perfect the structure of the compensation system by combining the actual situation. Besides, they should make adjustments on the compensation system continuously in accordance with the needs, enhance the effectiveness of compensation incentives and ultimately realize the goal of attracting, retaining and stimulating employees.

\section{REFERENCES}

[1] Liu Xin, Compensation Management (Third Edition) [M]. Beijing: China Renming University Press, 2011.

[2] Sun Ruidong, "Compensation Incentive Problems and Measures in SMEs" [J]. Corporation Research, 2012 (20).

[3] Wang Hui, "Innovative Compensation Management based on SMEs" [J].China Business and Trade, 2012 (5).

[4] Wang Hai, "Study on Compensation Incentive Problems and Measures in SMEs" [J], Technology and Market, 2013 (2).

[5] Wu Jingxiao, "Analysis on Compensation Management in SMEs" [J], Knowledge Economy, 2013 (12). 